\title{
Hypoxia-inducible factor $1 \alpha$ and ROCK1 regulate proliferation and collagen synthesis in hepatic stellate cells under hypoxia
}

\author{
YIBING HU, DANPING HU, HUANHUAN YU, WANGWANG XU and RONGQUAN FU \\ Department of Infectious Diseases, The Third Affiliated Hospital of Wenzhou Medical University, \\ Wenzhou, Zhejiang 325200, P.R. China
}

Received May 16, 2017; Accepted February 27, 2018

DOI: $10.3892 / \mathrm{mmr} .2018 .9397$

\begin{abstract}
Hypoxia serves a critical role in the pathogenesis of liver fibrosis. Hypoxia-inducible factor $1 \alpha$ (HIF1- $\alpha$ ) is induced when cells are exposed to low $\mathrm{O}_{2}$ concentrations. Recently, it has been suggested that Rho-associated coiled-coil-forming kinase 1 (ROCK1) may be an important HIF1- $\alpha$ regulator. In the present study, it was analyzed whether crosstalk between HIF1- $\alpha$ and ROCK1 regulates cell proliferation and collagen synthesis in hepatic stellate cells (HSCs) under hypoxic conditions. For this purpose, a rat hepatic HSC line (HSC-T6) was cultured under hypoxic or normoxic conditions, and HIF1- $\alpha$ and ROCK1 expression was measured at different time points. Additionally, HSC-T6 cells were transfected with HIF1- $\alpha$ small interfering RNA (siHIF1- $\alpha$ ), and measured protein expression and mRNA transcript levels of $\alpha$-smooth muscle actin, collagen $1 \mathrm{~A} 1$ and ROCK1. Collagen 3A1 secretion was also measured by ELISA. Cell proliferation was assessed by the MTT assay under these hypoxic conditions. The results indicated that a specific ROCK inhibitor, Y-27632, increased HIF1- $\alpha$ and ROCK1 expression over time in HSC-T6 cells in response to hypoxia. In addition, knockdown of HIF1- $\alpha$ inhibited HSC-T6 proliferation, suppressed collagen 1A1 expression, decreased collagen 3A1 secretion and attenuated ROCK1 expression. Notably, ROCK1 inhibition caused HSC-T6 quiescence, suppressed collagen secretion and downregulated HIF1- $\alpha$ expression. Collectively, these findings indicated that the interplay between HIF1- $\alpha$ and ROCK1 may
\end{abstract}

Correspondence to: Dr Rongquan Fu, Department of Infectious Diseases, The Third Affiliated Hospital of Wenzhou Medical University, 108 Wansong Road, Rui'an, Wenzhou, Zhejiang 325200, P.R. China

E-mail: frq6688@126.com

Abbreviations: HSCs, hepatic stellate cells; $\alpha$-SMA, $\alpha$-smooth muscle actin; COL1A1, collagen type $1 \alpha 1$ chain; COL3A1, collagen type $3 \alpha 1$ chain; RT-qPCR, reverse transcription-quantitative polymerase chain reaction; DMEM, Dulbecco's modified Eagle's medium; FBS, fetal bovine serum; MTT, 3-(4,5-dimethylthiazol-2-yl)-2,5-diphenyltetrazolium bromide

Key words: hypoxia inducible factor 1- $\alpha$, Rho-associated coiled-coil-forming kinase-1, HSCs, hypoxia, collagen be a critical factor that regulates cell proliferation and collagen synthesis in rat HSCs under hypoxia.

\section{Introduction}

Hepatic fibrosis is a common consequence of chronic liver diseases of various etiologies, such as hepatitis virus, alcoholic liver disease (ALD), non-alcoholic steatohepatitis (NASH), and others (1). The development of liver fibrosis encompasses activation of hepatic stellate cells (HSCs) and their crosstalk with liver parenchymal cells, such as hepatocytes and biliary epithelial cells (2). HSCs become activated and differentiate into myofibroblasts, thus playing a critical role in the production of collagen and excessive accumulation of extracellular matrix (ECM), which are two main features of hepatic fibrogenesis (3). Liver fibrosis is a form of chronic liver injury that is strongly associated with hypoxia. Moreover, exposure of HSCs to hypoxia affects development of hepatic fibrosis $(4,5)$.

During the past decades, increasing evidence has suggested that overexpression of hypoxia-inducible factor $1-\alpha$ (HIF1- $\alpha$ ) is closely associated with liver fibrogenesis (6-8). Indeed, overexpression of HIF1- $\alpha$ in vitro results in HSC activation and upregulation of genes associated with matrix deposition (9). HIF1- $\alpha$ and collagen 1A1 (Col1A1) expression increase in HSCs under hypoxia $(4,10)$. Transfection with short interfering RNA against HIF1- $\alpha$ (siHIF1- $\alpha$ ) prevents human HSC migration (7), while upregulation of HIF1- $\alpha$ is associated with viral hepatitis-derived fibrosis, HSC activation, and mitogen activated protein kinase (MAPK) activity (11). Additionally, expression of fibrogenic mediators is decreased in bile duct ligated HIF1- $\alpha$-knockout mice compared to controls (6). Altogether, this strong evidence indicates that HIF1- $\alpha$ is highly involved in hepatic fibrosis; however, the underlying regulatory mechanism is still not fully understood.

Previously, it was reported that the Rho/Rho-associated coiled-coil-forming kinase 1 (ROCK1) pathway is involved in HSC activation (12). Furthermore, ROCK inhibition with Y-27632 was demonstrated to suppress HSC proliferation and type I collagen production (13). Several studies have clearly indicated that there is crosstalk between ROCK 1 and HIF1- $\alpha$ (14-16). However, the relationship between HIF1- $\alpha$ and ROCK 1 in HSCs remains unexplored.

In the present study, we measured changes in HIF1- $\alpha$ and ROCK1 expression in HSCs under hypoxia at different 
time points. In order to functionally address the role of HIF1- $\alpha$ in HSC proliferation and collagen synthesis, and the interplay between HIF1- $\alpha$ and ROCK1 signaling, we performed knockdown experiments using siRNA transfection. Finally, we investigated whether ROCK1 inhibition mediates HIF1- $\alpha$-derived HSC activation, thus providing an attractive target for the treatment of hepatic fibrosis.

\section{Materials and methods}

Cell culture. The HSC-T6 cell line was maintained in room air or in hypoxic conditions $\left(1 \% \mathrm{O}_{2}\right)$ in an incubator at $37^{\circ} \mathrm{C}$. HSC-T6 cells were cultured in Dulbecco's modified Eagle's medium (DMEM) containing 10\% fetal bovine serum (FBS; both Gibco; Thermo Fisher Scientific, Inc. Waltham, MA, USA), $100 \mathrm{U} / \mathrm{ml}$ penicillin, and $100 \mu \mathrm{g} / \mathrm{ml}$ streptomycin. Culture medium was changed every $24 \mathrm{~h}$, and the ROCK1 inhibitor, Y-27632 (100 $\mu \mathrm{M})$ (Merck KGaA, Darmstadt, Germany ), was added.

siRNA transfection. One day prior to transfection, HSC-T6 cells were seeded in 6 -well plates at a density of $2 \times 10^{5}$ cells per well or in 96-well plates at a density of $1 \times 10^{4}$ cells per well. Cells were transfected with $100 \mathrm{nM}$ siHIF1- $\alpha$ or mock siRNA (as a control) (Shanghai GenePharma Co., Ltd., Shanghai, China) using Lipofectamine 2000 (Invitrogen; Thermo Fisher Scientific, Inc.) according to the manufacturer's instructions. Briefly, Lipofectamine-siRNA was incubated for $20 \mathrm{~min}$ before being added to cells. The transfection medium was replaced with fresh medium after $6 \mathrm{~h}$ and cells were collected after another $48 \mathrm{~h}$ for the follow-up tests.

Enzyme linked immunosorbent assay (ELISA). We measured secreted collagen 3A1 (Col3AI) using a commercially available ELISA kit (Uscn Life Sciences, Inc., Wuhan, China). After cells were transfected with siRNA or treated with the ROCK1 inhibitor, supernatants were collected at $48 \mathrm{~h}$. Samples were added into wells according to the manufacturers' instructions. The optical density (OD) values were read at $450 \mathrm{~nm}$ with an ELISA reader. The Col3A1 concentration was measured using a standard curve diagram.

Immunofluorescence detection. HSC-T6 cells were cultured in hypoxic conditions at $37^{\circ} \mathrm{C}$ as described above, and then collected at 0,12 and $48 \mathrm{~h}$. The cells were fixed in $4 \%$ paraformaldehyde for $15 \mathrm{~min}$, permeabilized with $0.1 \%$ Triton X-100 for 15 min and blocked with $4 \%$ bovine serum albumin (BSA) for $1 \mathrm{~h}$. Cells were incubated with a mouse $\alpha$-smooth muscle actin ( $\alpha$-SMA) antibody diluted 1:100 in phosphate buffered saline (PBS) for $1 \mathrm{~h}$ and then washed with PBS three times. Next, cells were incubated with Fluorescein Isothiocyanate (FITC) conjugated anti-mouse secondary antibody diluted 1:200 for $1 \mathrm{~h}$ and washed with PBS. After mounting with anti-fade mounting medium, cells were observed and fluorescent images were taken using a fluorescence microscope.

Western blot analysis. All protein concentrations were quantified using a BCA protein assay kit (Beyotime Institute of Biotechnology, Haimen, China). $30 \mu \mathrm{g}$ protein was loaded into $8-10 \%$ gradient SDS-PAGE gels, and transferred to a polyvinylidene difluoride membrane (EMD Millipore, Billerica, MA, USA). Membranes were blocked with $5 \%$ skimmed milk for $1 \mathrm{~h}$ and then incubated with primary antibodies ( $\beta$-actin, HIF1- $\alpha$, ROCK1, $\alpha$-SMA, CollA1, and Col3A1) at $4^{\circ} \mathrm{C}$ overnight. Goat anti-mouse $\mathrm{IgG}$ or anti-rabbit IgG (Jackson, USA) conjugated to horseradish peroxidase was then added for $1 \mathrm{~h}$ at $37^{\circ} \mathrm{C}$. Finally, antibody binding was developed using an Odyssey infrared scanner and Western Bright ECL reagents (Thermo Fisher Scientific, Inc.). Samples were washed three times with $1 \mathrm{X}$ Tris buffered saline and $0.1 \%$ Tween-20 (TBS/T).

$R N A$ isolation and reverse transcription-quantitative polymerase chain reaction ( $R T-q P C R)$. Total cellular RNA was extracted with TRIzol reagent (Invitrogen; Thermo Fisher Scientific, Inc.), and cDNA synthesis was performed using random hexamers with $1.0 \mathrm{mg}$ RNA. RT-qPCR was performed using SYBR-Green I (Toyobo Life Science, Osaka, Japan). The reaction mixture volume was $20 \mu \mathrm{l}$. Primer sequences were as follows:

$\beta$-actin (131) forward, 5'-CGTAAAGACCTCTATGCCAAC A-3' and reverse, 5'-GGAGGAGCAATGATCTTGATCT-3'; HIF-l $\alpha$ (36) forward, 5'-GTCGGACAGCCTCACCAAACA GAGC-3' and reverse, 5'-GTTAACTTGATCCAAAGCTCT GAG-3'; Collal (95) forward, 5'-GTACATCAGCCCAAA CCCCAAG-3' and reverse, 5'-CGGAACCTTCGCTTCCAT ACTC-3'; Col3Al (88) forward, 5'-GACTGCCCCAACCCA GAGATC-3' and reverse, 5'-TACCATCAGGAATGACAG GAGCAG-3'; $\alpha$-SMA (77) forward, 5'-GTGCTGTCCCTC TATGCCTCTGG-3' and reverse, 5'-GGCACGTTGTGAGTC ACACCATC-3'; ROCK1 (123) forward, 5'-CGGTATCTCTAC ATGGTGATGGAG-3' and reverse, 5'-ATCCAATGCAAG AACTACTTCTGC-3'

All PCR reactions were normalized to $\beta$-actin. Relative quantification of gene expression is shown using the $2^{-\Delta \Delta C q}$ method.

MTT assay. Cells were cultured at a density of $1.0 \times 10^{4}$ cells per well in 96-well plates (each group with 6 duplicates) for $24 \mathrm{~h}$. Then, cells were either transfected with siRNA or treated with the ROCK1 inhibitor, Y-27632, and incubated for 48 h. Thereafter, $50 \mu \mathrm{l}$ of MTT (5 mg/ml) (Nanjing KeyGen Biotech Co., Ltd., Nanjing, China) was added to each well and cells were incubated at $37^{\circ} \mathrm{C}$ in an incubator for another $4 \mathrm{~h}$. Finally, the medium was discarded and replaced with $150 \mu \mathrm{l}$ dimethyl-sulfoxide (DMSO). Once the violet crystal was dissolved, the OD of each well was measured using a microplate reader at a wavelength of $570 \mathrm{~nm}$.

Statistical analysis. Statistical analysis was performed using SPSS software (version 20.0; SPSS Inc., Chicago, IL, USA). Data are shown as mean \pm standard deviation, and statistical analysis was performed using one-way analysis of variance with Tukey's post hoc test for multiple comparisons. For comparison of two groups, t-tests were used. $\mathrm{P}<0.05$ was considered to indicate a statistically significant difference. Each experiment was repeated in triplicate. 


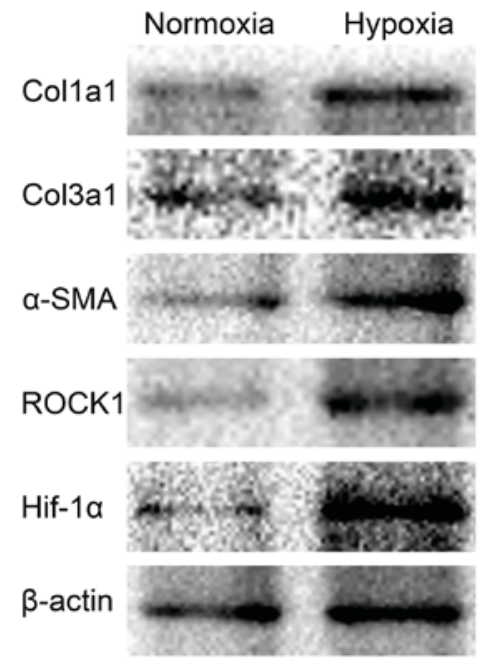

Figure 1. Effect of $1 \% \mathrm{O}_{2}$ on Col1A1, Col3A1, $\alpha$-SMA, HIF1- $\alpha$ and ROCK1 expression in HSC-T6 cells. HSC-T6 cells were incubated under normoxic or hypoxic conditions $\left(1 \% \mathrm{O}_{2}\right)$ and collected $48 \mathrm{~h}$ later. Col1A1, Col3A1, $\alpha$-SMA, HIF1- $\alpha$ and ROCK1 protein expression were then measured by western blotting. Col1/3 A1, collagen type $1 / 3 \alpha 1$ chain; $\alpha$-SMA, $\alpha$-smooth muscle actin; HIF1, hypoxia inducible factor 1; ROCK, Rho-associated coiled-coil-forming kinase 1.

\section{Results}

Hypoxia influences collagen synthesis and activation of HSCs and expression of HIF1- $\alpha$ and ROCK1. It is well known that hypoxia can promote a stem cell-like phenotype in multiple myeloma cells $(17,18)$. To investigate the effect of hypoxia on collagen synthesis and activation of HSCs, western blotting was used to detect the level of Col1A1, Col3A1 and $\alpha$-SMA protein. Cells were cultured under normoxia or hypoxia condition for $48 \mathrm{~h}$. Compared with normoxia group, the expression of Col1A1, Col3A1 and $\alpha$-SMA was increased in hypoxia group. We also found the different expression of HIF1- $\alpha$ and ROCK1 between normoxia and hypoxia conditions. Cells were both cultured for $48 \mathrm{~h}$, but the levels of HIF1- $\alpha$ and ROCK1 were upregulated under hypoxia condition. These results indicated that hypoxia could increase collagen synthesis, activated the HSCs, and induced the expression of HIF1- $\alpha$ and ROCK1 (Fig. 1).

The length of hypoxia influences collagen synthesis in HSCs. To analyze whether the length of hypoxia can phenotypically alter HSCs, we investigated the effects of different hypoxia time on HSC collagen synthesis in the HSC-T6 rodent cell line. Compared with the ' $12 \mathrm{~h}$ ' group, Col1A1 and Col3A1 protein expression were elevated in ' $24 \mathrm{~h}$ ' group when cells were exposed to hypoxia, suggesting that hypoxia increases expression of makers associated with matrix deposition with time (Fig. 2).

The length of hypoxia influences HSC activation. Next, we aimed to investigate whether length of hypoxia had an effect on the activation of HSCs. The cells were incubated under hypoxia for 0,24 and $48 \mathrm{~h}$. We measured levels of $\alpha$-SMA as a marker of HSC activation. We found an increase in $\alpha$-SMA protein expression using western blot and immunofluorescence

A

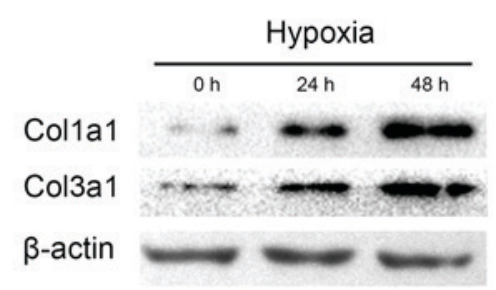

B

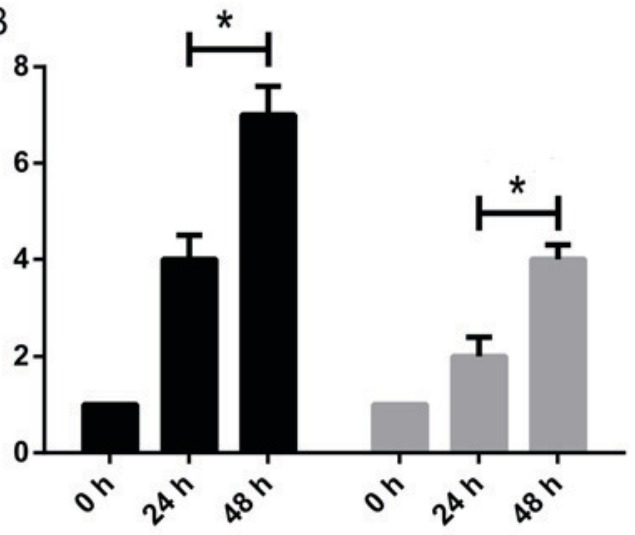

Figure 2. Effect of $1 \% \mathrm{O}_{2}$ on Col1A1 and Col3A1 expression in HSC-T6 cells over time. (A) HSC-T6 cells were incubated under hypoxic conditions $\left(1 \% \mathrm{O}_{2}\right)$ and collected at 0,24 and $48 \mathrm{~h}$ later. Col1 A1 and Col3A1 protein expression were measured by western blotting. (B) Relative protein expression $(\mathrm{n}=3)$. ${ }^{*} \mathrm{P}<0.05$, as indicated. Col1/3 a1, collagen type $1 / 3 \alpha 1$ chain.

A

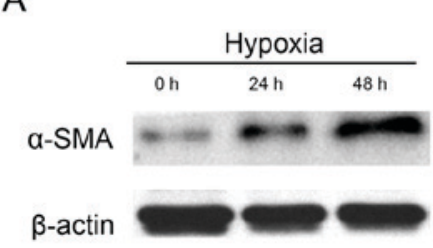

C

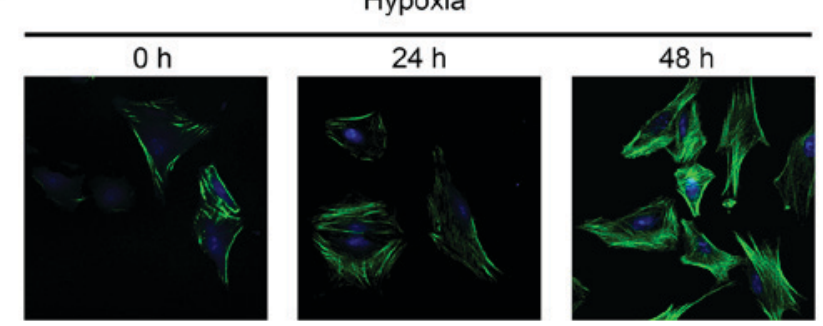

Figure 3. Effect of $1 \% \mathrm{O}_{2}$ on $\alpha$-SMA expression in HSC-T6 cells over time. (A) HSC-T6 cells were incubated under hypoxic conditions and collected at 0,24 and $48 \mathrm{~h}$ later. $\alpha$-SMA protein expression was measured by western blotting. (B) Relative protein expression $(n=3)$. (C) Comparison of $\alpha$-SMA expression at 0,24 and $48 \mathrm{~h}$ under hypoxia by immunofluorescence: Anti- $\alpha$-SMA (green) and DAPI (blue). Magnification, x400. Data are presented as the mean \pm standard deviation. ${ }^{*} \mathrm{P}<0.05$, as indicated. $\alpha$-SMA, $\alpha$-smooth muscle actin. analyses as the duration increased (Fig. 3). These data indicate that HSC are activated in response to hypoxia time.

The length of hypoxia influences HIFI- $\alpha$ and ROCKI upregulation in HSCs. Since HIF1- $\alpha$ and ROCK1 are associated with HSC activation and matrix deposition, we 
A

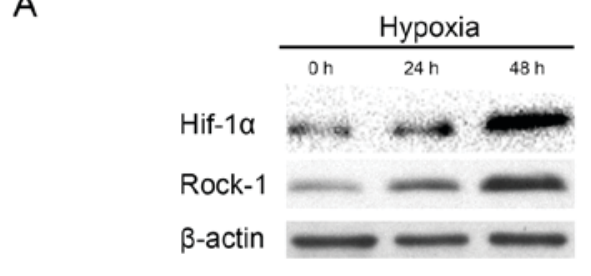

B

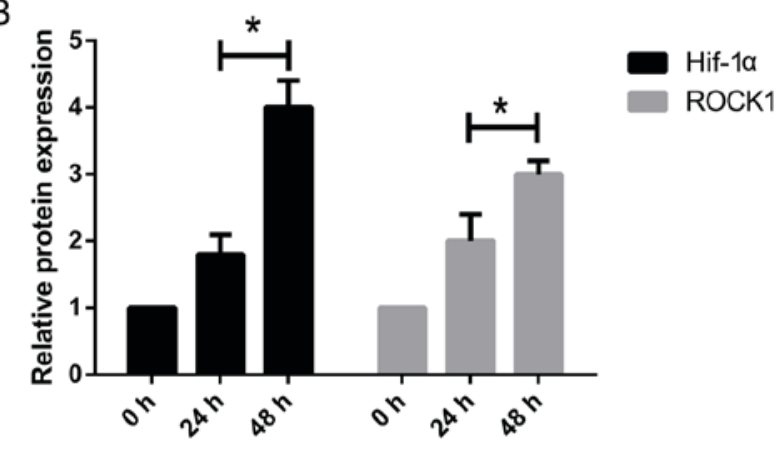

C

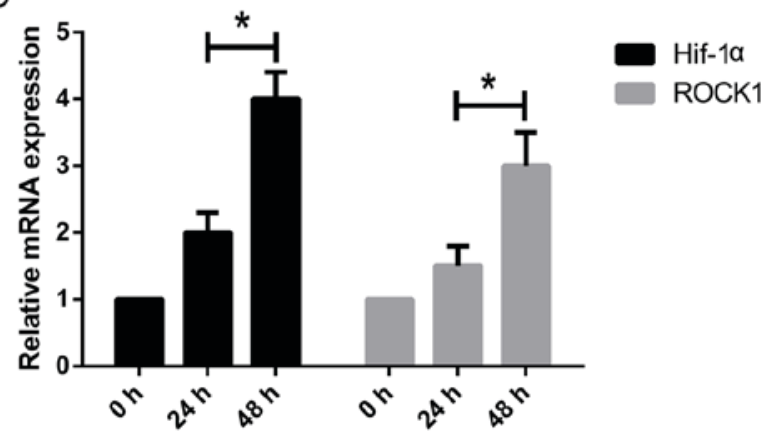

Figure 4. Effect of $1 \% \mathrm{O}_{2}$ on HIF1- $\alpha$ and ROCK1 expression in HSC-T6 cells over time. HSC-T6 cells were incubated under hypoxic conditions $\left(1 \% \mathrm{O}_{2}\right)$ and collected at 0,24 and $48 \mathrm{~h}$ later. (A) HIF1- $\alpha$ and ROCK1 protein levels were measured by western blotting. (B) Relative protein expression $(n=3)$. (C) HIF1- $\alpha$ and ROCK1 mRNA levels were measured by reverse transcription-quantitative polymerase chain reaction. Data are presented as the mean \pm standard deviation. $\mathrm{P}<0.05$, as indicated. HIF 1 , hypoxia inducible factor 1; ROCK, Rho-associated coiled-coil-forming kinase 1.

further investigated if there were changes in the mRNA and protein expression of HIF1- $\alpha$ and ROCK1 in HSC-T6 cells under different hypoxic conditions. Western blot analysis showed that HIF1- $\alpha$ and ROCK1 protein levels were increased in HSC-T6 cells with the increase of time (Fig. 4A-B). Accordingly, the RT-PCR analysis showed that HIF1- $\alpha$ and ROCK1 mRNA expression increased 3-fold and 2-fold, respectively, compared to untreated HSC-T6 cells at $0 \mathrm{~h}$ (Fig. 4C). These data suggest that HIF1- $\alpha$ and ROCK1 may play an important role in HSC activation.

Knockdown of HIF1- $\alpha$ inhibits ROCK1 expression and HSC activation under hypoxia. Next, we investigated if HIF1- $\alpha$ alters hypoxia-induced activation of HSC-T6 cells. HSC-T6 cells were cultured under hypoxic conditions. siHIF1- $\alpha$ was transfected into cells to silence HIF1- $\alpha$ expression. HSC-T6 cells were transfected with SiHIF1- $\alpha$ for $48 \mathrm{~h}$ and $\alpha$-SMA expression was measured. Our results showed that knockdown of HIF1- $\alpha$ decreased $\alpha$-SMA protein and mRNA expression (Fig. 5A-B). Accordingly, knockdown of HIF1- $\alpha$ also attenuated expression of Col1A1, a typical marker of
A

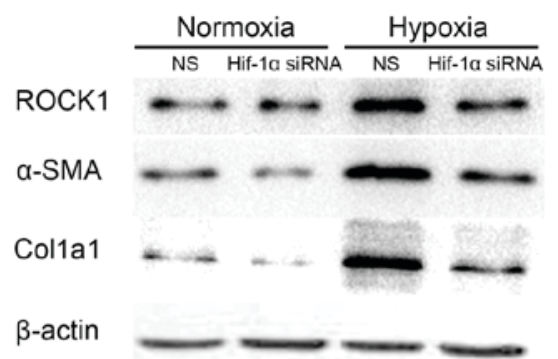

B

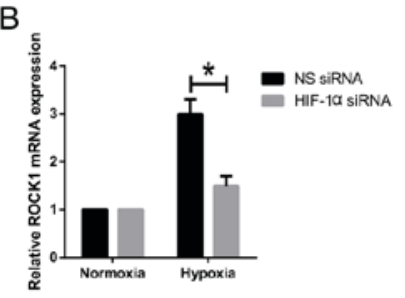

C
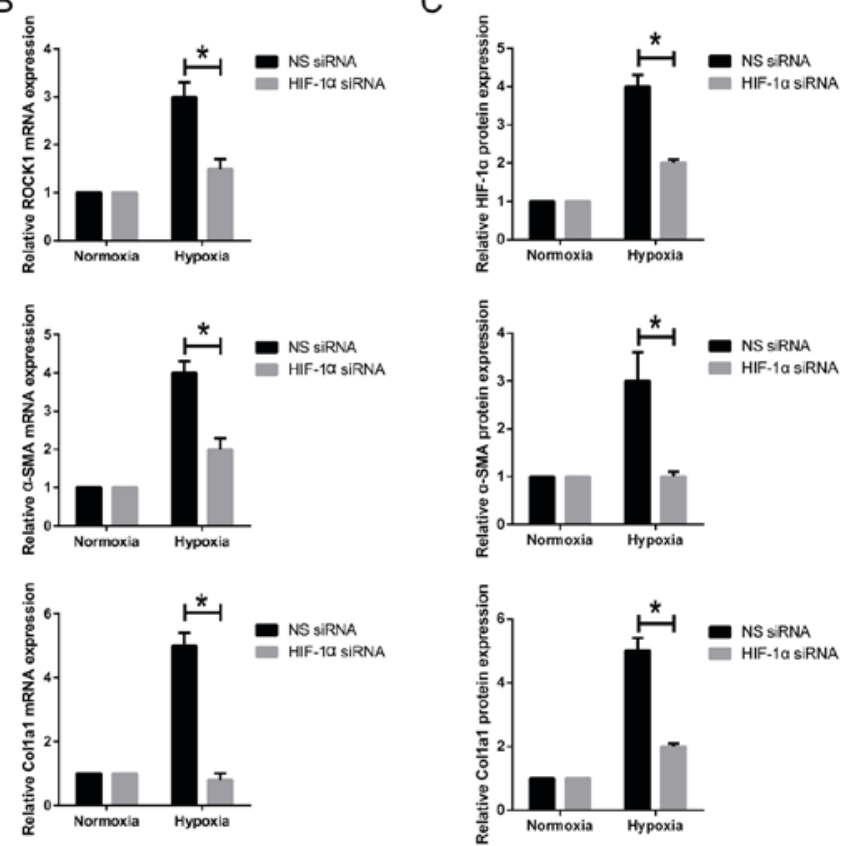

D

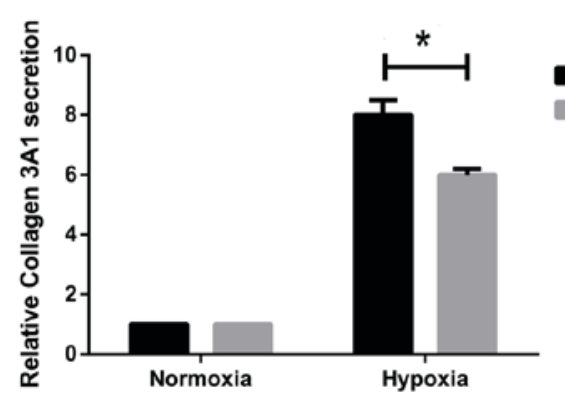

Figure 5. Effect of HIF1- $\alpha$ knockdown on ROCK1 expression and HSC activation under hypoxia. HSC-T6 cells were transfected with siHIF1- $\alpha$ and non-specific siRNA. (A) ROCK1, $\alpha$-SMA and Col1A1 protein levels were measured by western blotting. (B) ROCK1, $\alpha$-SMA and Col1A1 mRNA levels were measured by reverse transcription-quantitative polymerase chain reaction. (C) Relative protein expression ( $n=3)$. (D) Col3A1 secretion was measured by ELISA. Data are presented as the mean \pm standard deviation. ${ }^{*} \mathrm{P}<0.05$, as indicated. HIF1, hypoxia inducible factor 1 ; ROCK, Rho-associated coiled-coil-forming kinase 1; HSC, hepatic stellate cell; si, small interfering; Col1/3 A1, collagen type 1/3 $\alpha 1$ chain; $\alpha$-SMA, $\alpha$-smooth muscle actin; NS, non-specific; ELISA, enzyme linked immunosorbent assay.

activated HSCs (Fig. 5). Col3A1 secretion was decreased when cells were transfected with siHIF1- $\alpha$ under hypoxia (Fig. 5D). Additionally, we measured ROCK1 expression in siHIF1- $\alpha$-transfected HSC-T6 cells. We found that ROCK1 protein expression and mRNA levels were markedly downregulated following HIF1- $\alpha$ knockdown (Fig. 5A-C). Taken together, these findings indicate that decreasing HIF1- $\alpha$ 
A

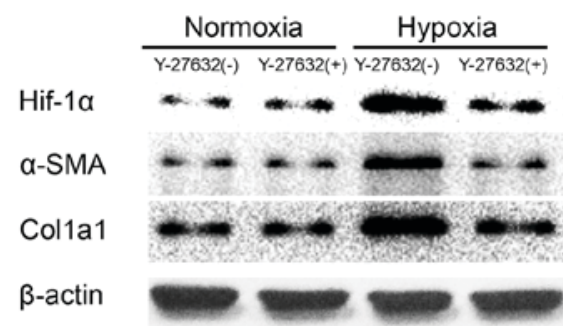

B
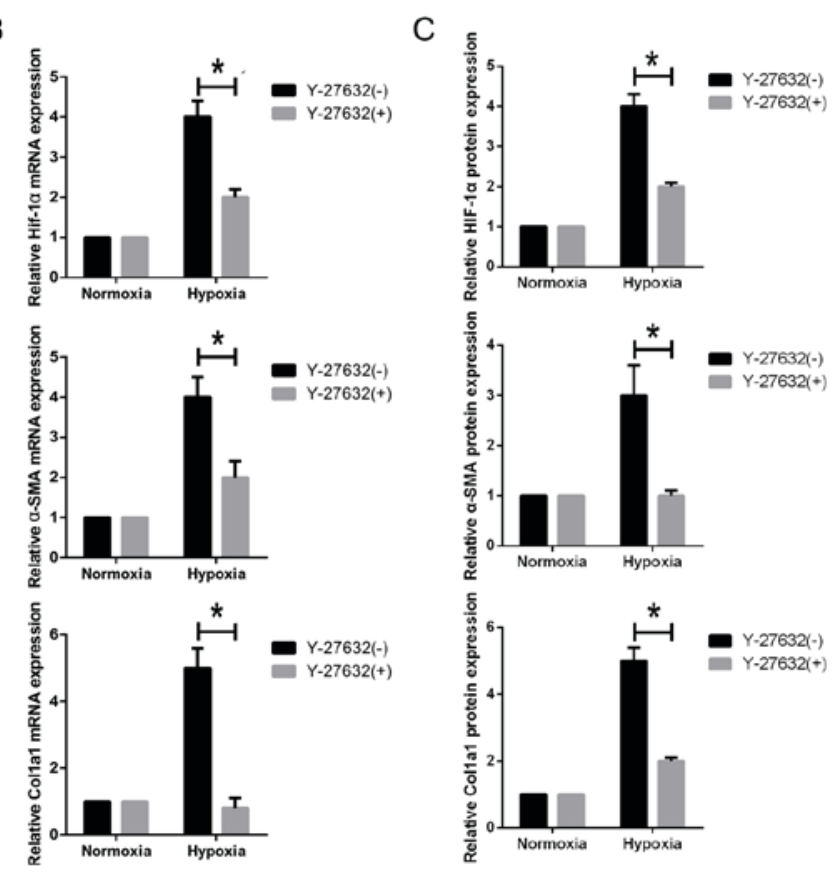

$\mathrm{D}$

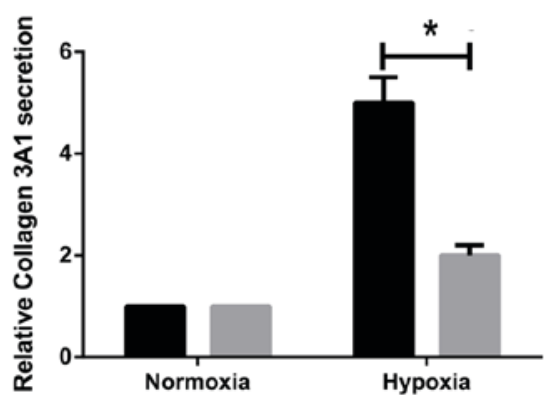

Figure 6. Effect of ROCK-1 inhibition on HIF1- $\alpha$ expression and HSC activation under hypoxia. HSC-T6 cells were challenged with Y-27632, a specific ROCK1 inhibitor. (A) HIF1- $\alpha, \alpha$-SMA, Col1A1 and Col3A1 protein levels were measured by western blotting. (B) HIF1- $\alpha, \alpha$-SMA and Col1A1 mRNA levels were measured by reverse transcription-quantitative polymerase chain reaction. (C) Relative protein expression $(n=3)$. (D) Col3A1 secretion was measured by ELISA. Data are presented as the mean \pm standard deviation. ${ }^{*} \mathrm{P}<0.05$, as indicated. HIF1, hypoxia inducible factor 1; ROCK, Rho-associated coiled-coil-forming kinase 1; HSC, hepatic stellate cell; Col1/3 A1, collagen type 1/3 $\alpha 1$ chain; SMA, smooth muscle actin; ELISA, enzyme linked immunosorbent assay.

expression attenuates ROCK1 expression and HSC activation in response to hypoxia.

Inhibition of ROCK1 downregulates HIF1- $\alpha$ expression and HSC activation under hypoxia. Next, we evaluated whether ROCK1 is required for hypoxia-induced activation of HSC-T6 cells. We inhibited ROCK1 activity using Y-27632, a specific ROCK1 inhibitor. We observed that

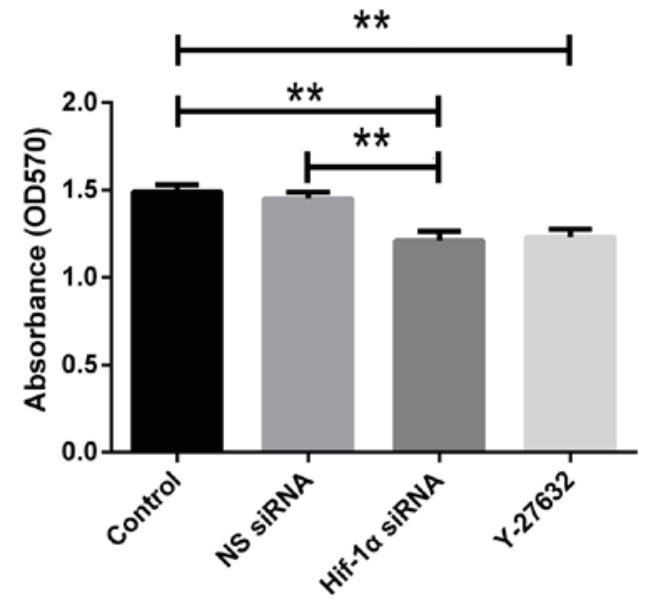

Figure 7. Effect of HIF1- $\alpha$ and ROCK1 on HSC proliferation under hypoxia. HSC-T6 cells were transfected with siHIF1- $\alpha$ or challenged with Y-27632, a specific inhibitor of ROCK1, and cell proliferation was measured by a MTT assay. Data are presented as the mean \pm standard deviation. ${ }^{* *} \mathrm{P}<0.01$, as indicated. HIF1, hypoxia inducible factor 1; ROCK, Rho-associated coiled-coil-forming kinase 1 ; HSC, hepatic stellate cell; si, small interfering; NS, non-specific.

ROCK1 inhibition decreased $\alpha$-SMA protein expression and mRNA levels in HSCs under hypoxic conditions (Fig. 6A-C). Similarly, western blot and RT-PCR analyses showed that Col1A1 was downregulated in response to ROCK1 inhibition (Fig. 6A-C). When cells were treated with the inhibitor under hypoxia conditions, Col3A1 secretion was concomitantly decreased, as shown by ELISA (Fig. 6D). Interestingly, HIF1- $\alpha$ protein expression and mRNA transcript levels were decreased in hypoxia-exposed HSC-T6 cells compared to cells incubated under normoxic conditions (Fig. 6A-C). Our data collectively demonstrate that HIF1- $\alpha$ activation in HSCs cultured under hypoxic conditions is ROCK1-dependent.

Effect of HIF1- $\alpha$ and ROCK1 on HSC proliferation under hypoxia. HIF1- $\alpha$ and ROCK1 are essential in cancer cell proliferation. Here, we determined if HIF1- $\alpha$ and ROCK1 are required for proliferation of hypoxia-exposed HSC-T6 cells using the MTT assay. We observed that the proliferation of cells was reduced after transfection with HIF1- $\alpha$ siRNA compared with control one. The proliferation was also suppressed in cells added Y-27632 compared with control group (Fig. 7). Our results collectively indicate that knockdown of HIF1- $\alpha$ or inhibition of ROCK1 significantly decreases HSC proliferation.

\section{Discussion}

Liver fibrosis is a reversible inflammatory response characterized by HSC activation and, consequently, excessive ECM accumulation. Constant hepatic fibrogenesis can result in major clinical outcomes including portal hypertension, ascites, esophageal varices, and cirrhosis. Understanding the etiology of fibrogenesis is critical for reversing hepatic fibrosis $(3,19)$. Numerous molecular pathways have been associated with liver fibrogenesis. Hence, it is crucial to characterize the pathogenesis of hepatic fibrosis in order to identify novel therapeutic strategies. 
Hypoxia is an early event in liver injury (6). Indeed, several studies have shown that hypoxia is associated with the initiation and progression of hepatic fibrosis $(5,6)$. Hypoxia induces HIF1- $\alpha$ activation, which has important effects on malignant cancers $(20,21)$. Moreover, HIF1- $\alpha$ plays determinant roles in cardiac development, pulmonary hypertension, diabetes and cancer, such as colorectal, pancreatic and ovarian cancers (22-26). Recently, the role of HIF1- $\alpha$ in hepatic fibrosis has gained considerable attention (27). Moreover, the RhoA/ROCK1 cascade is related to HSC activation and ECM deposition $(28,29)$. However, the crosstalk between HIF1- $\alpha$ and ROCK1 in HSC regulation remains unexplored.

In the present study, we investigated whether HIF1- $\alpha$ expression influences cell proliferation and collagen synthesis in HSCs in response to hypoxia. Our experiments clearly show that HIF1- $\alpha$ expression is upregulated in activated HSCs under hypoxia. The expression was elevated with hypoxia time increasing. Additionally, transfection of HSCs with siHIF1- $\alpha$ decreased HSC activation, suggesting that HIF1- $\alpha$ is directly related to HSC activation, consistent with previous studies (7).

Recently, Kutscher et al (30) found that HIF1- $\alpha$ is required for endothelial progenitor cell functions, including proliferation, invasion and cell survival. Hu et al (31) suggested that HIF1- $\alpha$ might be a new therapeutic target for rheumatoid arthritis as it prevents interactions of synovial fibroblasts with $\mathrm{T}$ and B cells. In another study, Marhold et al (32) revealed that HIF1- $\alpha$ is critical for maintaining quiescence in cancer stem cells. According to these data, HIF1- $\alpha$ may have additional roles in different systems. HSC activation has been linked to collagen deposition (1). In the present study, we detected increased levels of collagen under hypoxia. When cells were exposed to hypoxia longer, the collagen expression was induced more. Importantly, silencing HIF1- $\alpha$ expression decreased collagen deposition and secretion; however, matrix deposition was not completely suppressed, suggesting that other factors apart from HIF1- $\alpha$ affect HSC activation.

Therefore, we further explored the potential interplay between HIF1- $\alpha$ and ROCK1 during HSC activation under hypoxia. Wojciak-Stothard et al (33) showed that activation of RhoA/ROCK1 is enhanced under hypoxia in human pulmonary artery endothelial and smooth muscle cells. Due to the involvement of the RhoA/ROCK1 signaling pathway in numerous fibrotic processes, Knipe et al (34) suggested that further studies are necessary to shed light on the function of this pathway in fibrogenesis. In our study, upregulation of ROCK1 was observed in response to hypoxia in HSCs. Due to the increasing hypoxia time, ROCK1 expression was increased. Furthermore, ROCK1 inhibition attenuated HSC proliferation and collagen synthesis. Interestingly, specific ROCK1 inhibitors were effective in relieving inflammatory pain (35) and improving spinal cord injury (36).

Our results demonstrate that HIF1- $\alpha$ expression is also reduced in HSCs challenged with a ROCK1 inhibitor, suggesting that upregulation of HIF1- $\alpha$ is partly ROCK1-dependent. Conversely, silencing HIF1- $\alpha$ suppressed ROCK1 activation in HSCs. These results strongly support crosstalk between HIF1- $\alpha$ and ROCK1 in response to hypoxia. In view of the functions mentioned above, the interplay between HIF1- $\alpha$ and ROCK1 is associated with HSC activation. Recently, Gilkes et al (14) indicated that hypoxia might induce HIF1- $\alpha$ activation via RhoA-ROCK1 expression, resulting in increased breast cancer cell motility. In human ovarian cancer cells, Ohta et al (16) showed that silencing RhoA, ROCK1 or ROCK2 decreased HIF1- $\alpha$ expression. Moreover, Yin et al (37) concluded that the role of HIF1- $\alpha$ in hypoxia-induced apoptosis was RhoA-dependent in a neuroblastoma cell line.

In conclusion, our data clearly indicate that there is crosstalk between HIF1- $\alpha$ and ROCK1 in HSCs under hypoxia. Moreover, our results suggest that this crosstalk is essential for regulating HSC activation, providing novel insights into the underlying mechanisms of hepatic fibrogenesis and potential therapeutic targets for treatment of liver fibrosis.

\section{Acknowledgements}

The authors would like to thank Medjaden Bioscience Ltd. (Hong Kong, China) for assisting in the preparation of this manuscript.

\section{Funding}

The present study was supported by The Natural Science Foundation of Zhejiang Province (grant no. LY14H030010).

\section{Availability of data and materials}

The datasets used and/or analyzed during the current study are available from the corresponding author on reasonable request.

\section{Authors' contributions}

$\mathrm{YH}$ and RF designed the study, and $\mathrm{YH}, \mathrm{DH}, \mathrm{HY}$ and $\mathrm{WX}$ performed the data analysis. YH and DH drafted and wrote the manuscript. RF revised the manuscript critically for intellectual content. All authors gave intellectual input to the study and approved the final version of the manuscript.

\section{Ethics approval and consent to participate}

Not applicable.

\section{Consent for publication}

Not applicable.

\section{Competing interests}

The authors declare that they have no competing interests.

\section{References}

1. Hernandez-Gea V and Friedman SL: Pathogenesis of liver fibrosis. Annu Rev Pathol 6: 425-456, 2011.

2. Rockey DC: Translating an understanding of the pathogenesis of hepatic fibrosis to novel therapies. Clin Gastroenterol Hepatol 11: 224-231.e1-5, 2013.

3. Lee UE and Friedman SL: Mechanisms of hepatic fibrogenesis. Best Pract Res Clin Gastroenterol 25: 195-206, 2011.

4. Corpechot C, Barbu V, Wendum D, Kinnman N, Rey C, Poupon R, Housset C and Rosmorduc O: Hypoxia-induced VEGF and collagen I expressions are associated with angiogenesis and fibrogenesis in experimental cirrhosis. Hepatology 35: 1010-1021, 2002 . 
5. Poli G: Pathogenesis of liver fibrosis: Role of oxidative stress. Mol Aspects Med 21: 49-98, 2000.

6. Moon JO, Welch TP, Gonzalez FJ and Copple BL: Reduced liver fibrosis in hypoxia-inducible factor-1alpha-deficient mice. Am J Physiol Gastrointest Liver Physiol 296: G582-G592, 2009.

7. Novo E, Povero D, Busletta C, Paternostro C, di Bonzo LV, Cannito S, Compagnone A, Bandino A, Marra F Colombatto S, et al: The biphasic nature of hypoxia-induced directional migration of activated human hepatic stellate cells J Pathol 226: 588-597, 2012.

8. Wang GL, Jiang BH, Rue EA and Semenza GL: Hypoxia-inducible factor 1 is a basic-helix-loop-helix-PAS heterodimer regulated by cellular O2 tension. Proc Natl Acad Sci USA 92: 5510-5514, 1995.

9. Copple BL, Bai S, Burgoon LD and Moon JO: Hypoxia-inducible factor-1 $\alpha$ regulates the expression of genes in hypoxic hepatic stellate cells important for collagen deposition and angiogenesis Liver Int 31: 230-244, 2011.

10. Novo E, Cannito S, Zamara E, Valfrè di Bonzo L, Caligiuri A, Cravanzola C,Compagnone A, Colombatto S, Marra F,Pinzani M and Parola M: Proangiogenic cytokines as hypoxia-dependent factors stimulating migration of human hepatic stellate cells. Am J Pathol 170: 1942-1953, 2007

11. Wang Y, Huang Y, Guan F, Xiao Y, Deng J, Chen H, Chen X, Li J, Huang $\mathrm{H}$ and Shi C: Hypoxia-inducible factor-1alpha and MAPK co-regulate activation of hepatic stellate cells upon hypoxia stimulation. PLoS One 8: e74051, 2013.

12. Kato M, Iwamoto H, Higashi N, Sugimoto R, Uchimura K Tada S, Sakai H, Nakamuta M and Nawata H: Role of Rho small GTP binding protein in the regulation of actin cytoskeleton in hepatic stellate cells. J Hepatol 31: 91-99, 1999.

13. Iwamoto $H$, Nakamuta M, Tada S, Sugimoto R, Enjoji $M$ and Nawata H: A p160ROCK-specific inhibitor, Y-27632, attenuates rat hepatic stellate cell growth. J Hepatol 32: 762-770, 2000.

14. Gilkes DM, Xiang L, Lee SJ, Chaturvedi P, Hubbi ME, Wirtz D and Semenza GL: Hypoxia-inducible factors mediate coordinated RhoA-ROCK1 expression and signaling in breast cancer cells. Proc Natl Acad Sci USA 111: E384-E393, 2014

15. Matoba K, Kawanami D, Okada R, Tsukamoto M, Kinoshita J, Ito $\mathrm{T}$, Ishizawa S, Kanazawa Y, Yokota $\mathrm{T}$, Murai $\mathrm{N}$, et al: Rho-kinase inhibition prevents the progression of diabetic nephropathy by downregulating hypoxia-inducible factor $1 \alpha$. Kidney Int 84: 545-554, 2013.

16. Ohta T, Takahashi T, Shibuya T, Amita M, Henmi N, Takahashi K and Kurachi H: Inhibition of the Rho/ROCK pathway enhances the efficacy of cisplatin through the blockage of hypoxia-inducible factor-1 $\alpha$ in human ovarian cancer cell. Cancer Biol Ther 13 25-33, 2012.

17. van den Beucken T, Koch E, Chu K, Rupaimoole R, Prickaerts P, Adriaens M, Voncken JW, Harris AL, Buffa FM, Haider S, et al: Hypoxia promotes stem cell phenotypes and poor prognosis through epigenetic regulation of DICER. Nat Commun 5: 5203 2014.

18. Barsoum IB, Smallwood CA, Siemens DR and Graham CH: A mechanism of hypoxia-mediated escape from adaptive immunity in cancer cells. Cancer Res 74: 665-674, 2014.

19. Bataller R and Brenner DA: Liver fibrosis. J Clin Invest 115 209-218, 2005

20. Semenza GL: Targeting HIF-1 for cancer therapy. Nat Rev Cancer 3: 721-732, 2003.

21. Ji RC: Hypoxia and lymphangiogenesis in tumor microenvironment and metastasis. Cancer Lett 346: 6-16, 2014.

22. Wigerup C, Påhlman S and Bexell D: Therapeutic targeting of hypoxia and hypoxia-inducible factors in cancer. Pharmacol Ther 164: 152-169, 2016.
23. Krishnamachary B, Berg-Dixon S, Kelly B, Agani F, Feldser D, Ferreira G, Iyer N, LaRusch J, Pak B, Taghavi P and Semenza GL: Regulation of colon carcinoma cell invasion by hypoxia-inducible factor 1. Cancer Res 63: 1138-1143, 2003.

24. Ball MK, Waypa GB, Mungai PT, Nielsen JM, Czech L, Dudley VJ, Beussink L, Dettman RW, Berkelhamer SK, Steinhorn RH, et al: Regulation of hypoxia-induced pulmonary hypertension by vascular smooth muscle hypoxia-inducible factor-1 $\alpha$. Am J Respir Crit Care Med 189: 314-324, 2014.

25. He G, Jiang Y, Zhang B and Wu G: The effect of HIF-1 $\alpha$ on glucose metabolism, growth and apoptosis of pancreatic cancerous cells. Asia Pac J Clin Nutr 23: 174-180, 2014.

26. Birner P, Schindl M, Obermair A, Breitenecker G and Oberhuber G: Expression of hypoxia-inducible factor 1alpha in epithelial ovarian tumors: Its impact on prognosis and on response to chemotherapy. Clin Cancer Res 7: 1661-1668, 2001.

27. Zhan L, Huang C, Meng XM, Song Y, Wu XQ, Yang Y and Li J: Hypoxia-inducible factor-1alpha in hepatic fibrosis: A promising therapeutic target. Biochimie 108: 1-7, 2015.

28. Murata T, Arii S, Nakamura T, Mori A, Kaido T, Furuyama H, Furumoto K, Nakao T, Isobe $\mathrm{N}$ and Imamura M: Inhibitory effect of Y-27632, a ROCK inhibitor, on progression of rat liver fibrosis in association with inactivation of hepatic stellate cells. J Hepatol 35: 474-481, 2001.

29. Tada S, Iwamoto H, Nakamuta M, Sugimoto R, Enjoji M, Nakashima Y and Nawata H: A selective ROCK inhibitor, Y27632, prevents dimethylnitrosamine-induced hepatic fibrosis in rats. J Hepatol 34: 529-536, 2001.

30. Kutscher C, Lampert FM, Kunze M, Markfeld-Erol F, Stark GB and Finkenzeller G: Overexpression of hypoxia-inducible factor-1 alpha improves vasculogenesis-related functions of endothelial progenitor cells. Microvasc Res 105: 85-92, 2016.

31. Hu F, Liu H, Xu L, Li Y, Liu X, Shi L, Su Y, Qiu X, Zhang X, Yang Y, et al: Hypoxia-inducible factor- $1 \alpha$ perpetuates synovial fibroblast interactions with $\mathrm{T}$ cells and $\mathrm{B}$ cells in rheumatoid arthritis. Eur J Immunol 46: 742-751, 2016.

32. Marhold M, Tomasich E, El-Gazzar A, Heller G, Spittler A, Horvat R, Krainer M and Horak P: HIF1 $\alpha$ Regulates mTOR signaling and viability of prostate cancer stem cells. Mol Cancer Res 13: 556-564, 2015.

33. Wojciak-Stothard B, Zhao L, Oliver E, Dubois O, Wu Y, Kardassis D, Vasilaki E, Huang M, Mitchell JA, Harrington LS, et al: Role of RhoB in the regulation of pulmonary endothelial and smooth muscle cell responses to hypoxia. Circ Res 110: 1423-1434, 2012.

34. Knipe RS, Tager AM and Liao JK: The Rho kinases: Critical mediators of multiple profibrotic processes and rational targets for new therapies for pulmonary fibrosis. Pharmacol Rev 67: 103-117, 2015.

35. Wang C, Song S, Zhang Y, Ge Y, Fang X, Huang T, Du J and Gao J: Inhibition of the Rho/Rho kinase pathway prevents lipopolysaccharide-induced hyperalgesia and the release of TNF- $\alpha$ and IL-1 $\beta$ in the mouse spinal cord. Sci Rep 5: 14553, 2015.

36. Dyck SM, Alizadeh A, Santhosh KT, Proulx EH, Wu CL and Karimi-Abdolrezaee S: Chondroitin sulfate proteoglycans negatively modulate spinal cord neural precursor cells by signaling through LAR and RPTPo and modulation of the Rho/ROCK pathway. Stem Cells 33: 2550-2563, 2015

37. Yin CP, Guan SH,Zhang B, Wang XX and Yue SW: Upregulation of HIF-1 $\alpha$ protects neuroblastoma cells from hypoxia-induced apoptosis in a RhoA-dependent manner. Mol Med Rep 12: 7123-7131, 2015. 